\title{
Where Does the Uncanny Reside?
}

Goldschmidt, Pippa, Gill Haddow, and Fadhila Mazanderani (eds.) 2020. Uncanny Bodies. Edinburgh: Luna Press Publishing. (284 pages)

IT HAS BEEN slightly over a hundred years since the publication of Freud's "The Uncanny". Since then, "The Uncanny" has played an important role in academic and literary circles and been enabling research and creative writing in diverse areas. In Uncanny Bodies, Pippa Goldschmidt, Gill Haddow and Fadhila Mazanderani bring together contributors to explore a wide range of areas relating to the uncanny, such as human and non-human bodies, illness and healing, organ transplantation, amputation and prothesis, robots and cyborgs. In doing so, they set out to "evoke" the uncanny and to "investigate" where it resides (II).

The anthology came out as a result of and a response to the Uncanny Bodies workshop which was organised in Edinburgh in 2018. While the anthology showcases samples of prose and poetry written during the workshop, it also enables academics to both respond to these samples and reflect on their research areas, thereby transgressing academic or stylistic boundaries. The anthology is divided into three main sections: "Pain, Illness and Healing", "Situating bodies: the uncanny in the city and the forest", and "Transforming bodies into Other". I liked the fact that the editors however only offer these sections as an initial guide,

(C) The authors. Published by Föreningen Lambda Nordica under the CC BY-ND license. 
enabling the reader to draw other themes and re-group them "as an uncanny exercise" (6).

The first section of the anthology, "Pain, Illness and Healing", focuses on the tropes of uncanny, ranging from chronic pain, the doubling of the body through illness and the embodied experience of reproductive loss to the uncanniness of the process of healing, and are all noteworthy. I want to focus on the very first chapter in this section, Dilys Rose's "Half Here, Half Where", which describes the paralysed body as uncanny, as I find the experience of alienation through second person narration in this story uncanny and eery. Rose narrates the experience of having a stroke and occupying the body as if "half girl [...], half ghost" (I9). The paralysis divides the body into two entities, one controlled by the brain and the other as "half-wooden, half-rag doll". Rose considers their paralysed self "absent" as "it might as well be a hologram" (20). The image of a hologram here indicates a ghostly presence within the body itself. While the brain may control the healthy half, the other half becomes both an absence and an ineffectual presence. Therefore, the paralysed half proves to be a double and a sense of otherness within the self that haunts the body and the mind. In doing so, the paralysed half exposes the vulnerability of the body to this otherness within.The second person narration of this story also reinforces the uncanniness for the reader. While the narrator distances themself from the story by saying "[y] ou were dizzy [and] half of you evaporated" (I9), the reader is drawn into the narrative. The narrative enables the reader to identify with the paralysed body, and therefore presents the reader with an uncanny experience of alienation through internalising the writer's act of paralysis.

While the first section is primarily focused on pain and illness, the chapters in "Situating bodies: the uncanny in the city and the forest" trace the uncanny through the city of Edinburgh and the forest. The chapters in this section do not simply "situate bodies" in a space, but situate bodies as the very site of uncanniness. Most notably, Donna McCormack's “The Haunted House, or the Other in the Self” explores how the haunted house and death are not simply linked as definitions of the uncanny, but also through the body as the space that houses the self. By 
blurring the boundaries between life and death through a discussion of vitality, McCormack discusses how organ transplantation exposes that the body is not "a self-contained entity" (I I 4 ) but that it is "always already bound by its own alterity" (I I5). In doing so, McCormack questions the boundaries of human embodiment and investigates the figure of the haunted house as the post-transplant body that is haunted by the "present absence" (I I 8 ) of both the self and the transplanted organ. I specifically liked the discussion of "the openness of self to other" (I20), as McCormack discusses how the very existence of the body depends on this openness, since its vulnerability to the other also brings forth the potentials of housing both the self and the other within.

The third section, "Transforming bodies into Other" attempts to locate the uncanny through an investigation of how technologies allow a transgression of the boundaries between human and non-human bodies such as prosthetic bodies, robots and cyborgs. I especially enjoyed Naomi Salman's "sur la comète", which narrates the story of "everyday cyborgs" Larsen and Oster, who augment their bodies with implants. Larsen modifies his body to develop an understanding of his own body, whereas Oster obtains his devices to develop "new senses" (235) into the external world. Larsen considers "being a cyborg mean[s] to stop being human" (222) while Oster perceives his cyborg-ness as a way of "improving the human condition" (208). The uncanniness of cyborg identity is further evident as the story is narrated as "everyday cyborgs in love" (230). Of all the incidents in the story, I found Oster's identity the most obvious trope of uncanny. Oster's cyborg-ness is already a paradox: the more cyborg qualities he obtains, the more humane he feels. However, the story also demonstrates how both Larsen and Oster are vulnerable to their devices, albeit in distinct ways, and suffer anxiety and/or loss of implant-acquired sense. Furthermore, Gill Haddow's response to "sur la comète" also provides an undeniable insight into understanding cyborg identity, as Haddow explores the embodiment and vulnerabilities of cyborgs.

Overall, Uncanny Bodies is a fascinating contribution to uncanny studies as the anthology extends and develops the trope of the uncanny 
and may prove to be indispensable considering the developing health and body technologies. While the editors set out to question the possibility of evoking the uncanny, they also prove the impossibility of residing uncanny in a single discipline. Uncanny Bodies responds to "the call for a different thinking of genre and text, and of the distinctions between the literary and the non-literary, academic and non-academic writing" (Royle 2003, I8).

DR MINE SEVINC

BURDUR MEHMET AKIF ERSOY UNIVERSITY

\section{REFERENCES}

Royle, Nicholas. 2003. The Uncanny. Manchester: Manchester University Press. 